\title{
Application of Error - Correcting Coding in Hydroacoustic Communication Channels
}

\author{
Boris I. Filippov* and Gennady A. Chernetskiy \\ Novosibirsk State Technical University \\ 20 Karl Marx, Novosibirsk, 630073, Russia
}

Received 04.07.2016, received in revised form 09.10.2016, accepted 19.01.2017

The paper considers the possibility of using error-correcting coding in hydroacoustic communication channels (HACC).Comparison of test results shows that errors substantially packaged, resulting in increase of error probabilities with the large multiplicity and the likelihood of receiving a code word without error. Results of comparative statistical studies of these codes on a channel model with impulse hindranceare listed. As a result of theoretical and practical studies of various structures of error protection device (EPD) to improve the noise immunity of equipment sonar communication systems (HACC) was selected the algorithm of error correction, which is based on convolutional code $R=1 / 2$ with block, the threshold, the iterative decoding. To ensure the independence of errors at the decoder input (decorrelation of error stream), the matrix interleaver are encouraged to use in the EPD.

Keywords: sonar communication channel, the transmission of digital information, error control coding, statistical characteristics of error stream.

Citation: Filippov B.I., Chernetskiy G.A. Application of error - correcting coding in hydroacoustic communication channels, J. Sib. Fed. Univ. Eng. technol., 2017, 10(3), 377-387 DOI: 10.17516/1999-494X-2017-10-3-377-387.

\section{Применение помехоустойчивого кодирования}

\section{в гидроакустических каналах связи}

Б.И. Филиппов, Г.А. Чернецкий Новосибирский государственный технический университет Россия, 630073, Новосибирск, пр. Карла Маркса, 20

В работе рассматриваются возможности использования помехоустойчивого кодирования в гидроакустических каналах связи (ГАКС). Для обоснования выбора параметров разрабатываемого устройства защиты от ошибок были исследованы статистические характеристики потока ошибок в ГАКС. Сравнение результатов тестирования показывает, что ошибки существенно пакетируются, следствием чего является увеличение вероятностей

(C) Siberian Federal University. All rights reserved

* Corresponding author E-mail address: Filippov-boris@rambler.ru 
ошибок большой кратности и вероятности приёма кодового слова без ошибок. Для выяснения характеристик пакетирования ошибок были рассчитаны распределения длин пакетов и длин интервалов между пакетами ошибок. Полученные результаты статистической обработки файлов с массивами ошибок в ГАСС дают основание считать, что в рассматриваемом случае имеет место дискретный канал связи с пакетированием ошибок, который может быть описан математической моделью дискретного канала связи (ДКС) с памятью. Показано, что в рабочей области значений вероятности ошибки на входе декодерар ${ }_{6 x}\left(\right.$ менее $\left.7 \cdot 10^{-2}\right)$ код $(1218,609)$ уступает коду $(404,202)$, который позволяет вместе с перемежением символов в канале обеспечить сравнительно лучшие условия исправления независимых ошибок. Кроме того, выбранный сверточный код $(404,202)$ с перемежителем практически не уступает в отномении импульсных помех каскадным кодам на основе коротких свёрточных кодов и ииклических кодов Рида-Соломона, обычно используемых в аппаратуре иифровой связи при более низкой вероятности ошибок в канале, чем в аппаратуре ГАСС. Приведены результаты сравнительных статистических исследований этих кодов на модели канала с импульсными помехами. В результате теоретических и практических исследований различных структур устройства защиты от ошибок (УЗО) для повышения помехоустойчивости аппаратуры гидроакустических систем связи (ГАСС) был выбран алгоритм исправления ошибок на основе свёрточного кода $R=1 / 2$ с блочным, пороговым, итерационным декодированием. Для обеспечения независимости ошибок на входе декодера (декорреляции потока ошибок) в УЗО предлагается использовать матричный перемежитель. Благодаря ему в канале связи символь кода считываются по столбиам матрицы изображения (256х192 четверичных символа), а запись в матрииу и считывание на входе декодера производится построчно.

Ключевые слова: гидроакустический канал связи, передача цифровой информации, помехоустойчивое кодирование, статистические характеристики потока ошибок.

\section{Introduction}

The most effective resource of ensuring high noise immunity complex communication system is the introduction of the redundancy, which is necessary to detect and correct errors, that occur during operation of the system and it's elements. The theoretical basis of effective usage of input redundancy is the theory of error-correcting coding.

As shown by experimental studies, the statistical characteristics of hydroacoustic communication channels (HACC) have their counterparts in the short-wave, FM and other radio channels with variable parameters [1]. Therefore, designed principles and protection methods for these channels from errors may be used also in communication systems employing HACC, of course, we should take into account the specific properties of spreading of the acoustic signal in the aqueous medium.

\section{Causes of errors in digital hydroacoustic communication channel}

Literature states, that statistical characteristics of sonar signals and noise have complex, often transient nature [2-5]. These parameters depend on ocean conditions: water temperature, salinity, depth, presence of currents, the weather at the surface, bottom structure, species composition and abundance of biological objects, vessel traffic, etc. ${ }^{\circ}$

An orientation and extension of the alleged link between the source and receiver of acoustic signals are crucial. Depending on the space orientation of the connection lines distinguish three main classes of hydroacoustic communication channels:

- Horizontal, when the communication line, which is connecting the source and the receiver, is in an angular sector less than $10^{\circ}$ relative to the horizontal; 
- Inclined, when the communication line, which is connecting the source and the receiver, is in the $10^{\circ}-35^{\circ}$ range of angles relative to the horizontal;

- Vertical, when the communication line, which isconnecting the source and the receiver, is in the angular sector $15^{\circ}-35^{0}$ from the vertical.

The length of vertical channels does not exceed 10-12 km. They are characterized by a weak manifestation of refraction, i.e. propagation path of rays between the source and receiver of signals close to a straight line. Ray trajectories remain rectilinear at the largest mean value differences of sound velocity depth, if output angles of rays of the signal source does not exceed $80^{\circ}$ degrees from vertical. Weak manifestation of multipath and fading are noted $[2,6]$; it indicates, that propagate from source to receiver signals have not significant (10-15\%) changes of amplitude and phase of the signal with ray paths, when they are located within a $25^{\circ}$ degree angle from the vertical.

In accordance with the above classification of the analyzed channel closer to the class of hydroacoustic communication channels inclined orientation [2].

In the process of propagation in aqueous medium sonar signal in channels with inclined orientation is changing its structure, which can be separated into amplitude and phase. Speaking of amplitude changing, it should be understood, firstly, changes signal level occur with increasing distance from the source, secondly, signal level fluctuations occur due to multipath effects and random changes of water environment gain.

Level change with increasing distance from the signal source associated with the expansion of the front and different types losses. The nature of these losses is well understood and described in the literature [3-6]. Without dwelling on their examination, we note that the main causes of acoustic energy losses are relaxation processes, the shear friction layer of water and scattering. Accounting for these losses made during the calculation of the energy corresponding to the link [7].

Fluctuations of level and phase of hydroacoustic signals associated with the statistical heterogeneity of the aquatic environment and they are a consequence of random changes of gain in the environment and the influence of multipath. Often, these fluctuations are called signal fading and take them to interference.

Interference in the sonar lines due to their nature are divided into three main classes: additive, multiplicative (fading) and the Doppler frequency shift. In turn, the additive noise are classified according to the statistical structure and the nature of origin. According to the statistical structure of the additive noise is divided into three groups: the fluctuation, pulsed (time concentrated) and harmonic (centered over the spectrum) [1].

The origin of the additive noise is divided into natural and technical. Among the additive noise of natural origin distinguish:

- dynamic noise which occurrence due to the dynamic processes happening in the ocean - the thermal motion of molecules, surface waves, the noise of the surf, by the collapse of air bubbles formed in the upper layer at the surface of water, when they falling in the wave crests, the blows rain drops on the surface;

- noises ice origin, caused by wind, flowing around roughness of ice surface, cracking of the ice cover, hummocking ice fields, flowing around passages of irregularities at lower boundary;

- biological noise associated with its origin life of three major groups of animals: invertebrates, fish and mammals; 
- seismic noise caused by tectonic processes in the Earth.

Interference technical origin is separated into its own; media noise; noises foreign vessels; offshore drilling rigs; pipelines; extraneous signals sonar systems (hydro lighthouses, echo sounders, sonars, sonar communication systems, etc.).

The noise in the ocean is a superposition of many individual fields of independent sources, and the propagation of sound from these sources to the measurement points are connected with a plurality of independent and random distortions. This makes it possible to characterize the noise of the ocean is often a normal (HACC) distribution.

Multiplicative interference (signal fading) occur in a random changing the amplitude $A(t)$ and phase $\varphi(t)$ of the sonar signal. From the viewpoint of reception fading signals, they are equivalent to an increase in noise power. They lead to a decrease in signal/noise ratio at the input of receiver. However, fading feature is that their impact, in contrast to the additive noise, can't be compensated for by increasing the power of the transmitted signal. Therefore, to assess the real noise immunity of signal reception and evaluation of the capacity of hydro-acoustic communication system it's necessary to know the laws of the distribution of instantaneous values of the level and phase of the signal at the input of receiver.

A large number of studies $[1,3-6,8,9]$, in which experimental and theoretical study of fluctuations of the amplitude and phase $\varphi(t)$ of the of hydroacoustic signals are performed, are known.

In most cases, it was noted, that values of signal's amplitudes are normally distributed or distributed by the laws of Rayleigh, Rayleigh-Rice [1]. Moreover, the parameters of distributions depend strongly on the structure and conditions of formation of sonar link: orientation with respect to the bottom and the surface, the distance between the signal source and the measurement point, patterns of antennas and others.

Disturbances associated with the manifestation of the Doppler effect, are a specific kind of interference. In the sonar system Doppler effect caused by relative movement between the emitting and receiving antennas (operating during vessel motion, drifting) and causes the difference frequency of the received signal from the transmitted frequency, resulting in a shift of the entire spectrum of frequencies by the value $f_{d}$, change of the spectral width and the duration of the signal. Shifting of the frequency spectrum can be taken into account in selecting the receiver bandwidth by increasing its value to $2 f_{d}$. The corresponding change in the instantaneous frequency and duration of the signal due to the Doppler effect in practical systems of digital data transmission are compensated by clock system. If the correct choice of equipment parameters, influence of the Doppler effect is reduced to decrease noise immunity of the reception by the introduction of some equivalent noise caused by the extension of the receiver bandwidth, and the synchronization system.

In [1] following assessment of probability characteristics and parameters of signals and interference are listed:

- A one-dimensional density function of the distribution of the noise level $W(U)$, estimates for the expectation $m_{U}$ and variance of the noise $\sigma_{U}^{2}$;

- A one-dimensional function of the level of the distribution density of the received signal sonar $W(U)$, evaluation of its mathematical expectation $m_{E}$, dispersion $\sigma_{E}^{2}$;

- A one-dimensional density function of the distribution phase of the received acoustic signals $W(\varphi)$, evaluation of its mathematical expectation $m \varphi$, dispersion $\sigma_{\varphi}^{2}$; 
- The normalized correlation function of the signal $R(\tau)$ amplitude and the correlation interval $\tau_{0}$.

However, results characterize more properties of sonar channels with vertical orientation. But methods of measurement parameters of signals and interference, their statistical processing applicable to hydroacoustic communication channels inclined [2] and the horizontal direction.

\section{The statistical characteristics of flow of errors in the equipment HACC}

To justify the choice of parameters of the developed error protection device have been investigated statistical characteristics of errors in the stream of hydroacoustic communication channel. By comparing samples of sent and received image frames have been received arrays of errors in channel of sonar communication systems (HACC).To do this, pixels of received and transmitted images were converted to primary streams of binary symbols, and by combining these streams by modulo two, they formed an array of errors in the frame image. In the process of converting frames of images, lines in violation of synchronization are excluded from consideration.

Four files with error arrays was obtained: ereMass1.txt, errMass2.txt, errMass3.txt, errMass4. txt. Each contains about $3 \cdot 10^{5}$ binary symbols. These files were used to determine the statistical characteristics of the error stream in real hydroacoustic communication channel, as well as tests for statistical error protection device.

Following characteristics were determined by:

- The average probability of error $p_{c p}$;

- Distribution of multiplicities of errors $t$ in the code word with length $n-P_{n}(t)$;

- Distribution of the lengths of the error packets $P\left(t_{\pi}\right)$;

- Distribution of lengths of the intervals between packages of errors $P\left(t_{\text {int }}\right)$.

Results of statistical processing of error arrays are listed below.

In Tables 1-4 the distribution of multiplicities of errors for the various values of average probability in a communication channel, were shown, wherein the error arrays were divided into codewords of length $n=100$ characters.

For comparison distribution of multiplicities of errors in communication channel with independent nature of errors was obtained on the assumption, that the probability of error is the average error probability errMass1.txt file $\left(p_{c p}=0,005\right)$. Results are shown in Table 5.

Comparison of results in Tables 1 and 5 shows that errors in file errMass1.txt ( $p_{\text {average }}=0,005$ ) significantly packaged, resulting in an increase in the probabilities of errors with a large multiplicity

Table 1. Distribution of multiplicities of errors $P_{n}(t)$ in errMass1 file

\begin{tabular}{|c|c|c|c|c|c|}
\hline Multiplicity & 0 & 1 & 2 & 3 & 4 \\
\hline 0 & 0,84691 & 0,02135 & 0,04468 & 0,04895 & 0,01018 \\
\hline 5 & 0,00558 & 0,01051 & 0,00361 & 0,00099 & 0,00230 \\
\hline 10 & 0,00131 & 0,00033 & 0,00164 & 0,00066 & 0,00033 \\
\hline 15 & 0,00000 & 0,00033 & 0,00033 & 0,00000 & 0,00000 \\
\hline
\end{tabular}

$\mathrm{p}_{\text {average }}=0,005 ; \mathrm{n}=100$ characters. 
Table 2. Distribution of multiplicities of errors $P_{n}(t)$ in errMass 2 file

\begin{tabular}{|c|c|c|c|c|c|}
\hline Multiplicity & 0 & 1 & 2 & 3 & 4 \\
\hline 0 & 0,91524 & 0,03909 & 0,02825 & 0,00723 & 0,00296 \\
\hline 5 & 0,00230 & 0,00131 & 0,00033 & 0,00033 & 0,00000 \\
\hline 10 & 0,00099 & 0,00033 & 0,00033 & 0,00066 & 0,00033 \\
\hline 15 & 0,00033 & 0,00000 & 0,00000 & 0,00000 & 0,00000 \\
\hline
\end{tabular}

$p_{\text {average }}=0,0019 ; n=100$ characters.

Table 3. Distribution of multiplicities of errors $P_{n}(t)$ in errMass 3 file

\begin{tabular}{|c|c|c|c|c|c|}
\hline Multiplicity & 0 & 1 & 2 & 3 & 4 \\
\hline 0 & 0,77957 & 0,08574 & 0,05486 & 0,03351 & 0,00591 \\
\hline 5 & 0,00591 & 0,00887 & 0,00361 & 0,00197 & 0,00526 \\
\hline 10 & 0,00131 & 0,00164 & 0,00033 & 0,00230 & 0,00066 \\
\hline 15 & 0,00033 & 0,00066 & 0,00000 & 0,00033 & 0,00000 \\
\hline
\end{tabular}

$p_{\text {average }}=0,0061 ; n=100$ characters.

Table 4. Distribution of multiplicities of errors $P_{n}(t)$ in errMass 4 file

\begin{tabular}{|c|c|c|c|c|c|}
\hline Multiplicity & 0 & 1 & 2 & 3 & 4 \\
\hline 0 & 0,19054 & 0,06110 & 0,06932 & 0,07454 & 0,05683 \\
\hline 5 & 0,04796 & 0,05552 & 0,04468 & 0,04763 & 0,04369 \\
\hline 10 & 0,03318 & 0,02825 & 0,02562 & 0,02070 & 0,01938 \\
\hline 15 & 0,02168 & 0,01643 & 0,01610 & 0,01577 & 0,01183 \\
\hline 20 & 0,01347 & 0,00788 & 0,01150 & 0,00657 & 0,00591 \\
\hline 25 & 0,00460 & 0,00263 & 0,00361 & 0,00230 & 0,00131 \\
\hline 30 & 0,00197 & 0,00197 & 0,00033 & 0,00066 & 0,00033 \\
\hline
\end{tabular}

$p_{\text {average }}=0,073 ; n=100$ characters.

Table 5. Distribution of multiplicities of errors $P_{n}(t)$ in channel with independent errors

\begin{tabular}{|c|c|c|c|c|c|}
\hline Multiplicity & 0 & 1 & 2 & 3 & 4 \\
\hline 0 & 0,60354 & 0,30511 & 0,07672 & 0,01279 & 0,00161 \\
\hline 5 & 0,00020 & 0,00003 & 0,00000 & 0,00000 & 0,00000 \\
\hline
\end{tabular}

$p_{\text {average }}=0,005 ; n=100$ characters.

and the probability of receiving code's word without errors. A similar pattern has error streams in other files: errMass2.txt, errMass3.txt, errMass4.txt. By the nature of errors on analyzed images we can assume, that causes of errors packaging are: 
- understatement of the received signal level due to pumping, shipboard and manifestation of multipath propagation effects as a result of reflection from the inhomogeneities of the aquatic environment;

- interference with pulse character (possibly from the propeller serving vessel), which is especially characteristic for errMass3.txt, errMass4.txt (pronounced periodic interference with an interval of about 0.1 seconds).

To determine characteristics of packaging errorspacket length distribution and length of intervals between errors packages were calculated .

Figure 1 shows the average length of burst errors $\bar{t}_{\Pi I}$ and the average length of the interval between bursts of errors $\bar{t}_{\text {int }}$ from the base $\Delta t$ (distance between neighboring symbols of binary errors in the packet) for $\operatorname{errMass} 1 . t x t\left(p_{\text {average }}=0,005\right)$.

Actual average length of burst error and average length of interval between packets are defined by Fig. 1 as values, that are corresponding to the equity base $\Delta t$ and the average length of burst error (in this case is the point corresponding to $\Delta t=\bar{t}_{\Pi}=750$ binary symbols, wherein the mean interval between packets $\bar{t}_{\text {int }}=1800$ ).

Similarly errMass $3 . t x t$ file ( $p_{\text {average }}=0,0061$ ), the average burst error length is reduced to 480 characters, and the average distance between the packets of errors to 945 characters. In errMass 4 . txt file $\left(p_{\text {average }}=0,073\right)$ only condensation of errors can be identified with a period of about 350 binary digits.

Results of the statistical file processing error arrays HACC, give reason to assume that in this case there is a discrete communication channel bundling errors, which can be described by a mathematical model DKS memory [10].

By setting the average duration of a burst error can be determined $Q$, which characterizes the packetizing and error memory in discrete communication channel and has the following values:

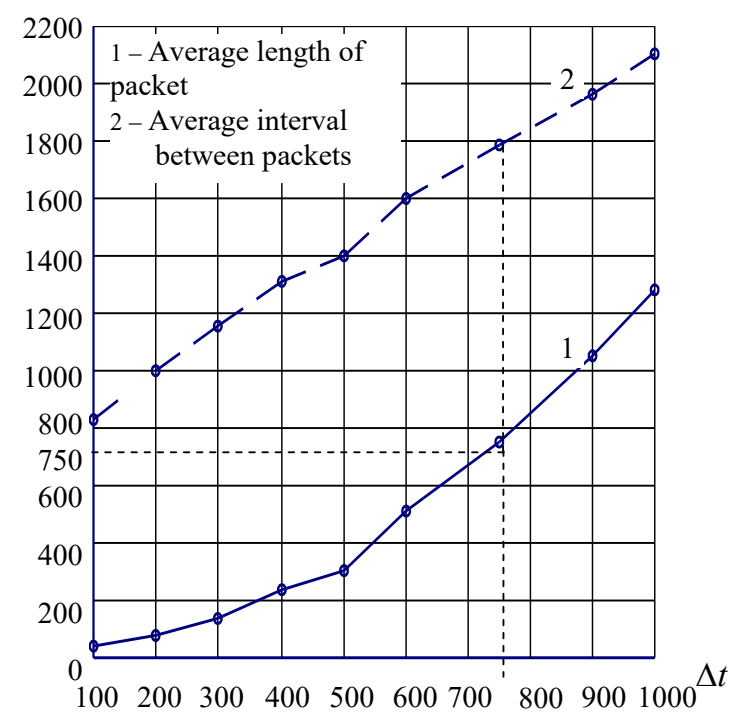

Fig. 1. Dependence of the average length of burst error, and the interval between packets of $\Delta t$

$$
-383-
$$




$$
\begin{aligned}
& Q=\frac{1}{\bar{t}_{\mathrm{r}}}=0,00125 \text { for errors in the array errMass } 1 . t x t \text { file, } \\
& Q=0,0021 \text { for errors in the array errMass } 3 . t x t \text { file. }
\end{aligned}
$$

\section{Selection of error-correcting code to implement the EPD}

The developed EPD should be built in sonar communication system and provides increased reliability of digital image transmission is not less than 100 times (the probability of errors in the received message should be reduced from $10^{-2}$ to $10^{-4}$ ). In the future, we will consider the codes to detect and correct errors due to it's own redundancy.

Preliminary tests of a number of cyclic codecs and convolutional codes in conditions where error statistics correspond to the real error streams recorded in the files: errMass1.txt, errMass $2 . t x t$, errMass3.txt (Fig. 1) showed that to correct errors in the existing channel HACC, taking into account the errors packaging needed noise-proof code, which speed $\mathrm{R} \leq 1 / 2$.

As correcting code errors in the EPD, cyclic BCH code with parameters $(n, k)=(204,96)$ may be used, correcting errors of multiplicity $t_{u} \leq 14$, which is at $P_{\text {input }}=6 \cdot 10^{-3}$ (memory $\mathrm{Q}=0,002$ communication channel) provides the probability of decoding errors $P_{d} \approx 5 \cdot 10^{-4}$. Convolution code (404.202) with a threshold iterative decoder in the same conditions provides $P_{d} \approx 2 \cdot 10^{-4}$.

To combat errors in the stacking EPD must be entered symbol of interleaver, which is known, allows to bring the channel to the channel characteristics with characteristics independent errors.

When setting the communication channel symbol interleaver and a cyclic code (204.96), and convolutional code (404.202) provide the required quality indicators $\left(P_{d}<10^{-4}\right)$, while for

$P_{d} \approx 5 \cdot 10^{-6}$ cyclic code, and convolutional code $P_{d} \approx 2 \cdot 10^{-7}$.

Based on these results, for the practical implementation of the EPD apparatus HACC selected convolutional code (404.202) with a threshold iterative decoder block type used in conjunction with the interleaver link characters.

Following featuresshould be in mind, when we use this code:

- Convolutional code decoder with iterative block type threshold unlike cyclic code allows the use of arbitrary length codeword $n \geq n_{0} \cdot \max [\operatorname{deg} g(x)]$. This allows for encoding information message use code words corresponding to the length of the string $256 \times 4=1024$ or the length of a column $192 \times 4=768$ of binary symbols;

- The computational complexity of decoding of the convolution code in less than $10 \div 15$ than the cyclic code with a decoder by the algorithm Berlikempa-Messi for binary codes;

- The quality of decoding the convolutional code decoder with iterative threshold is somewhat better than that of the cyclic code, which explains the additional internal interleaving effect inherent continuous convolutional codes;

- The lack of convolutional codes as continuous, is the need to transfer at the end of each frame "liner" in a random codeword to the decoder outputs the last information word. Otherwise, we have to put up with the fact that this word is in the memory of the decoder and is not given to the recipient, or will be forced to read without error correction.

The selected convolutional code (404.202) with the generating polynomial $g(x)=1+x^{7}+x^{27}+$ $+x^{76}+x^{113}+x^{137}+x^{155}+x^{156}+x^{170}+x^{202}$ and the code rate $R=1 / 2$ is one of the best canonical self- 
orthogonal codes, which have an orthogonal 10 checks and enables iterative decoding threshold. This medium-length code memory registers length decoder 202 in the cell.

Comparative tests of the selected convolutional code have been carried out (404.202) on the same convolutional code $\mathrm{R}=1 / 2$ of code rate (1218.609) having $\max [\operatorname{deg} g(x)]=609$. Test results are shown in Fig. 2.

It is evident that in the work area $p_{\text {input }}$ values (less than $7 \cdot 10^{-2}$ ) code (1218.609) concedes to code (404.202), which allows characters with channel interleaving to provide a relatively better conditions correcting independent errors. Moreover, the selected convolutional code (404.202) with an interleaver almost equal regarding impulse noise concatenated codes based on short convolutional codes and cyclic Reed-Solomon codes, which typically are used in the apparatus of a digital communication with a lower likelihood of errors in the channel than in an apparatus HACC. Table 6 and Fig. 3 show results of comparative statistical studies of these codes on a channel model with impulse noise.

In the course of these investigations on the computer it was assumed that the duration of a single pulse noise is approximately equal to the length of 300 binary digits, and the probability of error by the action of pulsed interference is 0.5 ; while the duration of impulse noise approximately corresponds to the duration of the periodic error packets in files: errMass3.txt, errMass4.txt.

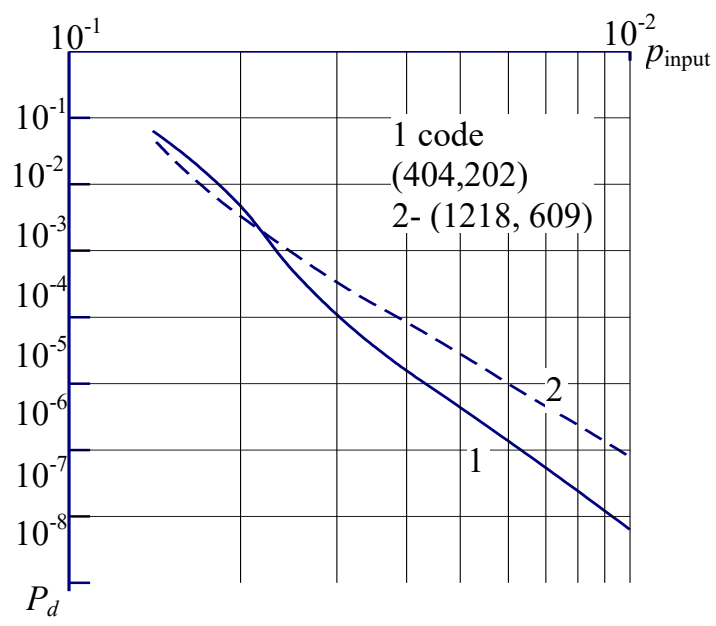

Fig. 2. Dependence of the probability of decoding error probability of $P_{d}$ errors $p_{\text {input }}$ decoder input

Table 6. The dependence of the probability of error decoding $P_{d}$ and probability occurrence of impulse noise $P_{i}$

\begin{tabular}{|c|c|c|c|c|c|c|c|c|}
\hline \multicolumn{9}{|c|}{$\begin{array}{l}\text { 1: convolutional code ( } 404.202) \text {, the threshold decoder, } 5 \text { iteration, the interleaver; } \\
2 \text { and 3: cascading code: Internal code convolution } \mathrm{R}=1 / 2 \text {, a Viterbi decoder, external - code Reed - Straw } \\
(255,239) \text {; } \\
\text { 3: internal - the same code Reed-Solomon code with interleaver; } \mathrm{p}=0,0007 \text { probability of independent errors. }\end{array}$} \\
\hline$P_{i}$ & 0,1 & 0,05 & 0,025 & 0,01 & 0,005 & 0,0025 & 0,001 & 0,0005 \\
\hline 1: $P_{d}$ & $1,7 \cdot 10^{-2}$ & $1,8 \cdot 10^{-3}$ & $6,0 \cdot 10^{-4}$ & $7,4 \cdot 10^{-5}$ & $1,2 \cdot 10^{-5}$ & $1,9 \cdot 10^{-7}$ & $9,9 \cdot 10^{-9}$ & \\
\hline 2: $P_{d}$ & $5,8 \cdot 10^{-2}$ & $1,1 \cdot 10^{-2}$ & $5,0 \cdot 10^{-3}$ & $1,6 \cdot 10^{-3}$ & $1,1 \cdot 10^{-3}$ & $4.0 \cdot 10^{-4}$ & $1,2 \cdot 10^{-4}$ & $7,0 \cdot 10^{-5}$ \\
\hline 3: $P_{d}$ & $4,4 \cdot 10^{-2}$ & $1,7 \cdot 10^{-2}$ & $7,0 \cdot 10^{-3}$ & $5,2 \cdot 10^{-3}$ & $2,8 \cdot 10^{-6}$ & $1,2 \cdot 10^{-7}$ & $2,1 \cdot 10^{-9}$ & \\
\hline
\end{tabular}




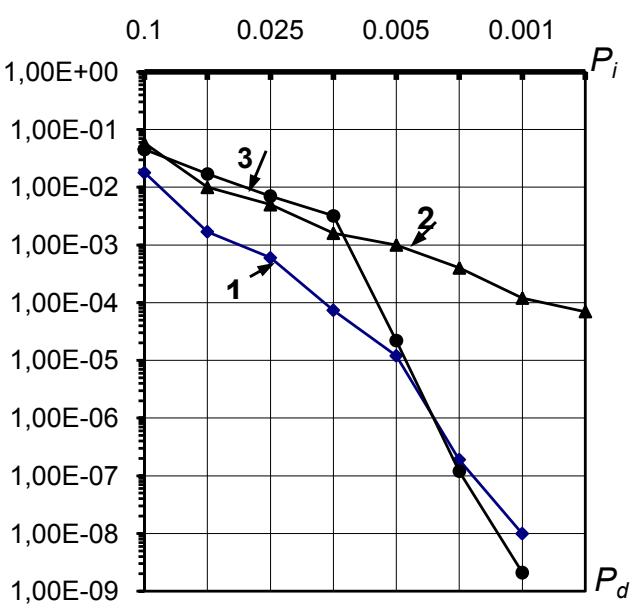

Fig. 3. Dependence of the decoding error probability and the probability of occurrence of impulse noise: $(1-$ convolutional code (404.202) with an interleaver, the decoder, 5 iteration threshold; 2 and 3 - concatenated code: internal convolution code is $\mathrm{R}=1 / 2$, a Viterbi decoder, appearance - a Reed-Solomon code $(255,239)$ in inner Embodiment 3 - the same code Reed-Solomon interleaver)

It can be seen that the convolution code (404.202) from the interleaver in the range of operating values HACC system failure probability is not inferior to the cascade code, and taking into account the complexity and concatenated code decoding rate convolutional code with iterative decoding threshold is more preferable.

Given results confirm the validity of the choice of a convolutional code (404.202) in conjunction with the interleaver of symbols, because, as noted, the cause of almost periodic interference HACC system can be precisely transients.

\section{Conclusions}

As a result of theoretical and practical studies of various structures of the EPD to improve the noise immunity of equipment HACC was selected error correction algorithm, which is based on convolutional code $\mathrm{R}=1 / 2$ block, the threshold, the iterative decoding. The block size is chosen to be the length of a column of the matrix picture $192 \cdot 4=768$ binary symbol. It is shown that in a channel with independent errors, this algorithm provides increased reliability more than two orders: the probability of the symbol error decreases with $3 \cdot 10^{-2}$ discrete communication channel to $10^{-4}$ at the output of the decoder.

To ensure the independence of errors at the decoder input (de-correlation error stream), in the EPD are encouraged to use the matrix interleaver. Thanks to it in the communication channel code symbols are read by columns of the image array (256x192 quaternary symbol) and the entry into the matrix, and reading is performed at the decoder input line.

\section{References}

[1] Филиппов Б.И., Чернецкий Г.А.Анализ статистических характеристик сигналов и помех в гидроакустических каналах связи. Журнал Вестник АГТУ. Серия Управление, вычислительная техника и информатика, 2015, 3, 78-84 [Filippov B.I., Chernetsky G.A. Analysis of statistical 
characteristics of signals and noises in hydroacoustic communication channels. J. AGTUbulletin. Management, computer facilities and informatics, 2015, 3, 78-84 (in Russian)]

[2] Филиппов Б.И. Определение наклонной дальности между судном и донной станцией. Журнал Вестник РГРТУ, 2016, 55, 33-40 [Filippov B.I. Determination of slant range between the ship and the bottom station. Herald Journal RSREU, 2016, 55, 33-40 (in Russian)]

[3] Чверткин Е.И. Гидроакустическая телеметрия в океанологии. Л.: Издательство ЛГУ, 1978, 14 c. [Chvertkin E.I. Hydroacoustic telemetry in oceanography. L.: Publisher LSU, 1978, 148 p. (in Russian)]

[4] Тарасюк Ю.Ф. Гидроакустическое телеуправление. Л.: Судостроение, 1985, 200 с. [Tarasyuk Y.F. Sonar remote control. L.: Shipbuilding, 1985, 200 p. (in Russian)]

[5] Матвиенко В.Н., Тарасюк Ю.Ф. Дальность действия гидроакустических средств. Л.: Судостроение, 1981, 213 с. [Matvienko V.N., Tarasyuk Y.F. The range of the sonar. L.: Shipbuilding, 1981, 213 p. (in Russian)]

[6] Чверткин Е.И. Гидроакустическая телеметрия во кеанологии. Л.: Издательство ЛГУ, 1978, 148 c. [Chvertkin E.I. Hydroacoustic telemetry in oceanography. L.: LGU Publisher, 1978, 148 p. (in Russian)]

[7] Филиппов Б.И. Энергетический расчёт гидроакустических линий связи. Журнал Вестник АГТУ. Серия Управление, вычислительная техника и информатика, 2016, 3, 81-91 [Filippov B.I. Energy calculation of hydroacoustic links. Herald Journal AGTU. Seriya Management, Computer Science and Informatics, 2016, 3, 81- 91(in Russian)]

[8] Митько В.Б., Евтюнов А.П., Гущин С.Е. Гидроакустические средства связи и наблюдения. Л.: Судостроение, 1982, 200 c. [Mitko V.B., Evtyunov A.P., Gushchin S.E.Hydroacoustic communication and surveillance. L.: Shipbuilding, 1982, 200 p. (in Russian)]

[9] Евтюнов А.П., Колесников А.Е. и др. Справочник по гидроакустике. Л.: Судостроение, 1982, 344 c. [Evtyunov A.P., Kolesnikov A.E. and others. Handbook of underwater acoustics. L.: Shipbuilding, 1982, 344 p. (in Russian)]

[10] Скляр Б. Цифровая связь. Теоретические основы и практическое применение, 2-е изд.: пер. с англ. М.: Изд. дом «Вильямс», 2003, 1104 с. [Sklyar B. Digital communication. Theoretical bases and practical application, 2 edition: The lane with English. M.: Prod. house "Williams", 2003, 1104 p. (in Russian)] 